\title{
Tunnel vision: The regulation of endocrine disruptors
}

\author{
JASON M. VOGEL \\ Environmental Studies Program, University of Colorado, UCB 397, Boulder, CO 80309, U.S.A., \\ E-mail:vogelman157@yahoo.com
}

Abstract. This study examines the failure of a small but significant element of U.S. chemical regulatory policy: the Endocrine Disruptor Screening Program (EDSP). A range of conditions are implicated in the failure of this program, but one condition, the scientific testing and regulation paradigm (STRP), seems particularly important and ties the failure of EDSP to the failure of other U.S. chemical regulatory programs. This paradigm is a group of assumptions that have driven pesticide (and other chemical) regulatory policy since World War II. This study investigates the relationship between STRP and the failure of EDSP, the potential efficacy of alternatives to this program, and one alternative that broke from this paradigm. Ultimately, this study suggests that we must revise the role of science in regulation in order to find effective alternatives to modern chemical regulatory policy.

\section{Introduction}

In 1996 Congress mandated the U.S. Environmental Protection Agency (EPA) to develop a program to test pesticides, commercial chemicals, and environmental contaminants for endocrine-disrupting effects and then to regulate those chemicals. EPA developed the Endocrine Disruptor Screening Program (EDSP) to address the mandate set forth in the Food Quality Protection Act of 1996 (FQPA). However, the mandated goal to protect public health from endocrine disruptors has been and will continue to be frustrated. Of the factors that contribute to this problem, the most important is a set of assumptions that constrains attention to ineffective policy alternatives; in other words, a dysfunctional regulatory paradigm has effectively displaced the mandated goal to protect public health. Real progress in solving this problem depends upon breaking out of the paradigm to consider other, more promising alternatives.

Why care about endocrine-disrupting chemicals? The human endocrine system, also known as the hormonal system, controls essential body functions ranging from gender differentiation during fetal development to the 'adrenaline rush' of extreme sports. Some chemicals, while posing no direct acute or chronic threat to humans or wildlife, ${ }^{1}$ still pose an indirect threat by interacting with the endocrine system of the organism - leading to unnatural, untimely, and perhaps excessive release or suppression of hormones, a phenomenon known as endocrine disruption (Colborn et al., 1996). Science has implicated endocrine-disrupting chemicals (EDCs) in reproductive infertility, sexual underdevelopment, altered or reduced sexual behavior, attention deficit/hyperactivity disorder, altered thyroid and adrenal cortical function, not to mention increased incidence of certain cancers and birth defects among other effects (Howdeshell, 2002; McLachlan and Arnold, 1996; Zoeller, 2002). So little is known about endocrine disruption that EPA estimates 87,000 chemicals already in commercial use need testing to determine if they affect the endocrine system (EPA, 2003a). Some of these chemicals are used as pesticides, and remain as residues on fresh and in processed foods we eat. Other common sources of exposure contribute 
to our total toxic load, including drinking water, lawn chemicals, consumer products, household insecticide use, etc.

Between 5 and 6 billion pounds of pesticide active ingredient are released into the global environment each year (Donaldson et al., 2002; Aspelin, 1994). EPA estimated that in 1999 U.S. pesticide use amounted to 1.2 billion pounds of active ingredient, or 4.3 pounds per person (Donaldson et al., 2002: p. 8). ${ }^{2}$ This massive chemical release occurs with very little understanding of the fate of residues in the environment, patterns of human and wildlife exposure, or their adverse health effects; and even less knowledge of the potential disruption of human and wildlife endocrine systems.

\section{The context of endocrine disruption}

One must examine three elements of the context to understand endocrine disruption and its policy significance thoroughly: the historical development of the scientific testing and regulation paradigm (STRP); the history of endocrine disruption science; and the complexity of endocrine disruption.

Since endocrine disruption is only part of the complex world of chemicals, working definitions will serve to clarify the following discussion. Chemical pollutants are defined as any synthetic chemical that humans release into the environment. Toxic chemicals are chemical pollutants with a direct acute or chronic health effect on humans or other organisms. Endocrine-disrupting chemicals refer to chemicals with indirect, hormone-related health effects. EDCs are not necessarily chemical pollutants since many natural compounds also have an effect on the endocrine systems of humans and wildlife. This article focuses on EDCs that are chemical pollutants, however, since any management of risks from endocrine-disrupting chemicals will likely focus on synthetic chemicals. Note that a chemical can be either a toxic chemical or an EDC, but may just as easily be both.

A persistent organic pollutant (POP) refers to a chemical pollutant that can persist for long periods of time in the environment. Chemical pollutants are persistent when they have resistance to degradation by mechanisms such as photolysis, chemical attack, or biological action. A pesticide refers to a specific use of a chemical - typically to kill crop pests such as insects, plants, fungi, or mammals. Although there are some pesticides made from natural plant residues or minerals, most pesticides used in large volume today are synthetic and thus chemical pollutants. Although a pesticide may be a toxic chemical or an EDC or both, there are many other uses of toxic chemicals and EDCs. This distinction of use derives from the compartmentalized legislation designed by Congress over the years to regulate pesticides separately from industrial pollutants or medical drugs for instance. The remainder of this study focuses on the endocrine-disrupting potential of pesticides to avoid unnecessary complication of the argument. The diverse and complex chemical universe remains important, just unnecessary for the purposes of this article. ${ }^{3}$

Scientific testing and regulation paradigm

The framing of pesticide regulation in this country began under several important conditions in the early 20 th century. ${ }^{4}$ First, government did not yet regulate in the sense of 
modern government regulation. Laissez-faire still dominated economic thought and the principle of a hands-off government had not yet been shaken by the Depression. Congress originally enacted pesticide regulation (in 1906 and 1910) to protect consumers from fraudulent claims about product purity or performance (Pure-Food Act, P.L. 59-384 and Insecticide Act, P.L. 61-152).

As Congress amended pesticide legislation after World War II, society viewed pesticides as a beneficial, problem-solving technology since DDT and other pesticides virtually eradicated several diseases in the U.S., including malaria, yellow fever, typhus, and dysentery. Government gave chemical companies free rein, and even encouraged the introduction of new chemicals to the marketplace as fast as possible with little concern for residual toxicity. By the time Rachel Carson focused people's attention on a threat to public and environmental health, pesticides were so prevalent, and the chemical industry so entrenched, that government and public health were on the defensive (see Wargo, 1996: chapters 2 and 3 for a good discussion of this history). Because pesticides provided a clear benefit, government and the public generally accepted that one must scientifically prove negative health effects before regulating a chemical. This placed the burden of accumulating extensive information on a growing number of compounds squarely on the shoulders of government. For the sake of clarity, I will refer to this established framework as the scientific testing and regulation paradigm for the remainder of this paper. ${ }^{5}$

As science developed to test chemicals for health effects in the 1940s and 1950s, the predominant concerns were direct acute and chronic health effects, especially cancer. This focus of the field of toxicology on direct health effects was rigidified in public policies when classic toxicology was incorporated as the scientific component of STRP. Endocrine-disrupting chemicals, by contrast, only lead to health consequences indirectly by mimicking or antagonizing chemicals native to the human body.

The scientific testing and regulation paradigm is a group of assumptions that have framed chemical regulatory policy since World War II. Among the assumptions are: (1) scientific determination of harm must precede regulatory action, (2) science has the capacity to determine harm with sufficient certainty, ${ }^{6}$ and (3) chemical exposure affects humans according to the assumptions of classic toxicology.

An important subtlety regarding this analysis deserves attention. By discussing STRP as a conditioning factor undermining EDSP, two levels of decision-making enter the discussion. On the one hand, this article critiques an ordinary decision process by assessing EDSP. However, the constitutive decision process (decision about how we make decisions) is suffused with the assumptions of STRP. Congress and EPA designed EDSP (the ordinary decision process) within the larger framework of STRP (a major component of the constitutive decision process). While we can readily perceive some alternatives to EDSP (see the Alternative approaches section below), the dysfunctions in STRP must be considered to determine the likelihood that any of those alternatives can or will affect outcomes.

\section{History of endocrine disruption science}

Sir Edward Charles Dodds, a British scientist, gathered scientific evidence on endocrine-disrupting effects as early as the 1930s, ultimately developing 
diethylstilbestrol (DES), a 'synthetic estrogen' eventually banned in the U.S. (Krimsky, 2000: p. 5). ${ }^{7}$ In 1950, two scientists in New York published a study that identified endocrine disruption in chickens. They studied chickens exposed to the pesticide DDT, a chemical very similar to DES, and discovered sexual underdevelopment and suppressed expression of secondary sex characteristics (Burlington and Lindeman, 1950). Burlington and Lindeman postulated a connection between DDT and estrogenic effects similar to those of DES. This suggested link between pesticides and endocrine-disrupting effects, however, remained scientifically dormant for decades.

Research on endocrine-disrupting effects accelerated in the late 1970s and early 1980s along two initially isolated pathways: human health effects and wildlife biology. John McLachlan spearheaded exploration of human health effects, extrapolating from his post-doctoral research connecting the effects of DES and DDT in 1971 (e.g., McLachlan, 1980, 1985; McLachlan and Newbold, 1987). Meanwhile, wildlife biologists began to recognize widespread and pervasive problems in certain wildlife populations after Rachel Carson brought attention to the detrimental effects of pesticides on wildlife in 1962: widespread population declines of song birds, eggshell thinning in predatory birds (most notably the bald eagle), reproductive failure and declining populations of otters, dolphins, other sea mammals, alligators, sea gulls, mink and other ecosystem consumers (Carson, 1962). The declines were too obvious and widespread to ignore, and scientists began searching vigorously for answers.

Theo Colborn integrated the science of wildlife ecology and human health studies after participating in a study of environmental degradation in the Great Lakes basin (Colborn et al., 1990). The idea of ecosystem-wide endocrine disruption due to environmental contamination first emerged in Colborn's 1990 study. Colborn then convened the Wingspread work sessions, bringing together researchers working in wildlife and human toxicology, endocrinology, anthropology, ecology, immunology, histopathology, anthropology, and wildlife management. These diverse experts explicitly discussed endocrine disruption and shared evidence across disciplines. One concrete result was the Wingspread consensus statement, a detailed formulation of the endocrine disruption hypothesis (Bern et al., 1991; Krimsky, 2000: chapter 1). The Wingspread consensus statement focused attention on the previously overlooked effects of chemical contamination besides cancer. Colborn's work and collaboration ultimately led to the publication of a book, Our Stolen Future, in March 1996, often referred to as the sequel to Rachel Carson's Silent Spring.

The endocrine system is one of the major communication systems in the human body. It uses molecules called hormones, to send signals to regulate sexual development, metabolism, puberty, a woman's menstrual cycle, bone growth, and a host of other body functions. A malfunctioning endocrine system can lead to diseases such as diabetes, growth hormone deficiency, osteoporosis, and to birth defects, altered or reduced sexual behavior, infertility, and sexual underdevelopment. Some synthetic chemicals have been created, often for use as pesticides, fertilizers, or other crop support, that interact with hormone receptor sites in the body. By 1996, scientists identified at least 51 such chemicals and chemical families, including DES, DDT, PCBs, dioxins, and furans (Colborn et al., 1996: p. 81). Research continues to uncover new endocrine-disrupting chemicals, and the list currently contains 87 chemicals and chemical families (Myers, 2003). The mechanisms of this interaction 
are poorly understood, but include: hormone mimicry, when the body is fooled into thinking there are hormone signals and hormone blocking, when a chemical blocks hormone receptor sites, so normal hormone signals are ignored. A third mechanism consists of a variety of effects whereby body chemicals or components which relate to endocrine function, such as enzymes that break down old hormones, are impaired or otherwise influenced, thus affecting the endocrine system without direct interaction with hormones or hormone receptors (an indirect, indirect effect). A chemical that behaves in one of these three ways is known as an endocrine-disrupting chemical, or an endocrine disruptor (Colborn et al., 1996: chapter 5).

The effects of EDCs on the human body differ substantially from poisoning or toxic exposure which may cause cancer, physiological birth defects, gene mutation, cell damage, or acute health effects such as nausea, vomiting, even death. Exposure to EDCs during critical stages of development can lead to gross birth defects or an increase in cancer susceptibility, but also to more subtle and possibly more pervasive problems such as infertility as an adult, attention deficit/hyperactivity disorders, immune system deficiencies, feminization of males, and masculinization of females (McLachlan and Arnold, 1996; Colborn et al., 1996). Additionally, because many EDCs accumulate in the fat reserves of mammals, the effects of endocrine-disrupting chemical contamination may amplify in animals near the top of the food web. Thus a female human may carry a toxic load of EDCs before she becomes pregnant, guaranteeing fetal exposure of her child. ${ }^{8}$ Studies have also determined that detectable levels of endocrine-disrupting chemicals exist in human breast milk, further exposing children during the most critical stages of post-natal development (e.g., Smith, 1999). Additionally, very low concentrations of and thus exposure to many EDCs has been found to cause dysfunction in humans and other organisms. These health effects may be pervasive throughout the planet due to fast and universal transport of chemicals through the world's atmosphere and oceans (Hemond and Fechner, 1994; NAS, 1993a: chapter 8).

\section{Scientific complexity and the failure of classic toxicology}

The complexity of endocrine disruption impedes the scientific testing and regulation of EDCs under EDSP. The notion of biomimicry is a complex biomolecular concept. It requires a base knowledge about the tertiary and quaternary structure of hormone receptors ${ }^{9}$ and the physiochemical interaction between hormones and receptors at this structural level. Only with this knowledge can the complexity of endocrine disruption, and its staggering consequent significance, be fully differentiated from the more easily appreciated effects of toxic chemicals (mostly cell damage or gross dysfunction). Although scientists understand the function of the endocrine system in some detail, the mechanisms of EDC action are complicated and poorly understood (Colborn et al., 1996: p. 137).

Chemicals may exhibit endocrine disruption only over longer time spans, or selectively during certain stages of development, or only in later generations (Colborn et al., 1996). Causation is difficult to establish, particularly for non-persistent chemicals. If a fetus exposed to endocrine-disrupting chemicals exhibits, for example, sexual dysfunction as an adult, genetics, environmental factors, psychological factors, and the 
entire history of potential exposure from the pre-natal period to adulthood must be accounted for adequately before causation can be established with a scientifically and/or legally acceptable level of certainty. Although statistical correlations may indicate potential causation, they cannot establish causation with confidence, especially as the temporal and spatial limits of the study expand, thus expanding the domain of alternative explanations. Differentiating the effects of synthetic endocrine-disrupting chemicals from natural, hormonally active plant residues presents an additional problem with establishing causation. Further difficulty arises with defining control groups on a planet that now has pervasive low doses of EDCs in even the most isolated environments.

A second impediment to scientific testing and regulation under EDSP involves the inappropriate application of classic toxicology to EDCs in the regulatory arena. At least three assumptions of classic toxicology fail when applied to endocrine disruption. ${ }^{10}$ Monotonic dose-response means that greater exposure to a chemical leads to a greater health effect. Uniformity of effect means that a chemical cannot have opposite effects. And the threshold effect means that no appreciable health effect occurs at lower level exposure.

The typical, linear dose-response relationship of classic toxicology (known as a monotonic dose-response) does not describe the action of most EDCs. A monotonic dose-response assumes that larger exposure to a chemical results in a more severe health effect. This assumption allows for more efficient scientific testing because smaller sample sizes yield statistically significant responses (e.g., cancer incidence rate) at higher doses. Linearly scaling these results down to typical exposure levels is assumed to yield approximate quantitative response rates (e.g., number of people per million who will develop cancer from exposure).

Low concentration exposure to some EDCs, however, causes an adverse effect, while a large amount of the same chemical can swamp the hormonal system and cause it to 'shut off,' effectively reducing or preventing the dysfunction. Scientists call this an inverted U dose-response (e.g., Cavieres et al., 2002; vom Saal et al., 1997). Other EDCs exhibit effects only at dilute and large concentrations, forming a U-shaped or J-shaped dose-response curve instead of a monotonic dose-response (National Toxicology Program, 2001). Because monotonic dose-response fails to explain the action of EDCs, it is inappropriate to make this assumption for regulation under EDSP.

The second assumption of classic toxicology is uniformity of effect, which assumes a chemical cannot have opposite effects, although it can have multiple effects. Certain endocrine-disrupting chemicals, however, do have opposite effects at different stages of an organism's development, and for other reasons. Dioxin, for example, exhibits an estrogen-like effect in fetal organisms, but exhibits an anti-estrogen effect in adults (U.S. Congress, 1992; Birnbaum, 1995). The severity of this problem proves difficult to determine because testing of humans and human fetuses is both statistically difficult and considered ethically unacceptable. Again, however, evidence contradicts the assumption.

The third assumption of classic toxicology is the existence of a threshold effect. Following the logic of monotonic dose-response, if decreased exposure always leads to decreased health risk, at some dilute dosage the health effect becomes infinitesimally 
small or effectively zero - the effect threshold. However, most hormones in the blood stream occur in dilute concentrations and even very dilute levels of EDCs can prove dangerous. The concentrations of EDCs that may affect a fetus during certain stages of development can be substantially smaller than the concentrations that affect adults, if they affect adults at all. Since EDCs do not follow monotonic dose-response curves and often exhibit greater effects at the lowest concentrations, the threshold assumption proves inappropriate for regulation as well.

Many peer-reviewed scientific studies document that the assumptions of classic toxicology fail to describe endocrine-disrupting behavior (Myers, 2003). Thus, the third assumption of the scientific testing and regulation paradigm (chemical exposure affects humans according to the assumptions of classic toxicology) breaks down. Nevertheless, classic toxicology drives much of the regulatory science called for in modern chemical regulatory programs. Although the assumptions of classic toxicology form a conceptual baseline for toxicologists, they imply an usory ravsal understanding when applied to EDCs in regulation. This does not mean science can play no role in protecting human and environmental health. On the contrary, the role of science is critical. However, a simplistic relationship between science and policy should not be assumed as in the second assumption of the scientific testing and regulation paradigm: science has the capacity to determine harm with sufficient certainty.

\section{The Endocrine Disruptor Screening Program (EDSP)}

The Food Quality Protection Act of 1996 (FQPA, P.L. 104-170: Title IV sec. 408p) and the Safe Drinking Water Act Amendments of 1996 (SDWA, P.L. 104-182: Title I sec. 136) mandated the creation of a program to investigate the potential effects of synthetic chemicals on the human endocrine system. ${ }^{11}$ EPA developed EDSP to address the mandate in FQPA. Legislation required the development of a program and test validation within two years of passage, program implementation in three years, and results reported to Congress within four years of August 3, 1996, when President Clinton signed FQPA into law. Finally, FQPA required EPA action to protect public health after developing and implementing screening and testing procedures. FQPA established an end and an instrumental goal for EDSP. The end goal: "the [EPA] Administrator shall, as appropriate, take action under such statutory authority as is available. . as is necessary to ensure the protection of public health" (FQPA, P.L. 104-170: Title IV sec. 408p, emphasis added). The instrumental goal was to "develop a screening program, using appropriate validated test systems and other scientifically relevant information, to determine whether certain substances may have...endocrine effects" (FQPA, P.L.104-170: Title IV sec. 408p, emphasis added).

Some progress has occurred on the instrumental goal; scientists continue to develop new testing procedures, and attempts to identify EDCs have accelerated and entered the mainstream (e.g., National Toxicology Program, 2001). But what of the end goal to protect public health? Progress on endocrine-disrupting science is not the end of this policy, and substituting the instrumental for the end goal risks further endangering public health. Few people exposed to chemicals that could threaten them or their 
young or unborn children would take comfort in the fact that scientific investigation continues with vigor but no regulation occurs.

Addressing the dilemma of endocrine disruption and chemical exposure does not distill into a polarized choice between public health and corporate profit. Some synthetic chemical use is prudent, important, and useful in protecting the food supply and for other important purposes. To assert an either/or conflict precludes the possibility of innovative policies that might effectively improve public health outcomes while also allowing the chemical industry to provide useful products, employ citizens, and make a profit while doing so. The issue at hand is that current chemical regulatory policy favors industry even under a Congressional mandate to protect public health. The National Research Council likewise observed: "The assumption of the null hypothesis as used in risk analysis [as in the case of regulating chemicals] contains an implicit bias because it places a greater burden of proof on those who would restrict than those who would pursue a hazardous activity, presuming these activities are safe until proven otherwise" (Stern and Fineberg, 1996: p. 25). This does not imply adoption of the so-called Precautionary Principle, which, in effect, simply reverses the burden of proof but maintains the dysfunctional assumption that science can determine harm with sufficient certainty. Although the current criticism of the scientific testing and regulation paradigm is not an argument for the Precautionary Principle, note that Congress singled out and explicitly prioritized the goal of protecting public health.

Currently, corporate interests dominate U.S. policy on chemical regulation often by emphasizing the need for scientific determination of harm. Science benefits financially from this orientation at the expense of public health (for an extensive discussion of these assertions see Fagin and Lavelle, 1999). But longer-term costs for science will certainly arise by silently allowing policy to overstate what science can accomplish. Ideally, an appropriate policy would protect public health to the greatest extent possible while allowing the chemical industry to produce important products at a profit and reorienting science to contribute to the goal of public health. But before looking at ideal policies, how well does EDSP address the goals set for it in FQPA?

After FQPA passed in August 1996, EPA organized the Endocrine Disruptor Screening and Testing Advisory Committee (EDSTAC) to provide recommendations on how to develop screening and testing procedures for EDCs. EDSTAC convened in October 1996 and continued to meet until the committee developed a final report in September 1998, which formed the basis for the establishment of EDSP (EPA, 2002). EPA accomplished only preparatory work on EDSP through 1998, thus failing to meet the first Congressional mandate to develop procedures by August 1998.

On August 3, 1999, the second legislated deadline for implementation of EDSP, several environmental and public health interest groups filed a lawsuit against EPA for noncompliance with the deadlines set forth in FQPA. The plaintiffs were the Natural Resources Defense Council, The Breast Cancer Fund, CalPIRG Charitable Trust, Pesticide Watch Education Fund, the Pesticide Action Network North American Regional Center, San Francisco Bay Physicians for Social Responsibility, and the United Farm Workers of America (AFL-CIO). The suit was settled out of court on March 30, 2000, establishing new deadlines for test development and testing implementation, with EPA accepting responsibility to communicate progress and reasons for potential delay to the plaintiffs (U.S. District Court, 2001). This consent decree 
has been amended several times. Its ultimate fate remains in limbo due to intense lobbying and legal action by industry and a withdrawal of executive support by the Bush administration (Olson et al., 2002).

EPA's successor to EDSTAC, the Endocrine Disruptor Methods Validation Subcommittee (EDMVS), anticipates the validation of all screening tests by the end of 2003, but the testing procedures, especially ecological testing, may take five to seven years after 2003 to validate. These estimates simply claim that the tests will be validated by this time, not that implementation or testing on suspected EDCs will be underway. Unfortunately, these new deadlines may prove no more realistic than those of the past. ${ }^{12}$ Thus, the procedures necessary to test for EDCs and to begin the process of legally removing them from use to prevent exposure will remain unavailable until sometime after 2005-2007. This is nine to eleven years after FQPA was passed, and seven to nine years after procedures were supposed to be developed (U.S. District Court, 2001: III, 7).

The trends in implementing EDSP are delay and slow-paced research to address the instrumental goal of EDSP: to develop and validate screening and testing procedures to identify endocrine-disrupting chemicals. The revised timelines for screening tests and procedures implies a significant delay in implementation of the scientific component of EDSP, with no certainty that the new timelines are any more realistic than previous ones. Any action on the goal that "the administrator shall, as appropriate, take action... to ensure the protection of public health" is postponed at least until EPA develops screening tests and procedures. However, action at that point is far from assured.

Even if this delay in implementation were overcome, substantive issues with the testing of endocrine-disrupting chemicals would still prevent meaningful action to protect public health. According to the EDSP web site, "[t]he universe of chemicals of concern to EPA as potential endocrine disruptors is estimated to number more than 87,000 items" (EPA, 2003b). Toxicity testing for each chemical requires such a large investment of time and other resources that thorough testing of all potential EDCs could never occur within an acceptable timeframe. Because of the complexities and uncertainties of endocrine disruption discussed above, however, even a massive effort at toxicity testing would have an indeterminate effect on the ability of science to causally establish harm from endocrine-disrupting chemicals. Klinke and Renn (2002) identify four types of uncertainty that help clarify the current argument. The four types are: variability (different responses from average by individuals or subgroups), systematic and random measurement errors (statistical confidence), indeterminacy (non-linear or stochastic responses), and lack of knowledge (ignorance of relevant variables or information). While concern only with the first two uncertainties might imply a relatively simple job for science in better quantifying risks from EDCs, the latter two uncertainties set a bar for science too high to regulate based on science alone - especially considering the difficulty of identifying causation given interaction and non-linear effects; social, economic, and psychological issues involved with exposure; and multiple valid interpretations of harm from existing exposure and risk data. In other words, increasing the commitment to scientific testing does not address the failure of classic toxicology or the resulting inadequacy of the assumption that science can determine harm with sufficient certainty. 
U.S. Congressman Mike Synar (D-OK), during a committee hearing on the safety of pesticides in foods stated another aspect of the problem succinctly: "Almost 20,000 pesticide products have been under review since 1972 and only 31 have been reregistered. At this rate it will take us to the year 15,520 A.D. to complete. I believe in good science. What I don't believe in is geologic time" (U.S. Congress, 1993). Congressman Synar's comments related only to re-review of chemicals currently on the market with established tests and testing for only standard toxicity. In comparison to the endocrine-disrupting chemical universe, the situation he refers to involves fewer chemicals, each with relatively less complicated mechanisms of health effects, and established toxicity tests. Yet this substantially easier task mathematically required over 13,000 years to complete testing, assuming no new chemicals went to market. The more complicated mechanisms of endocrine disruption, without validated tests, and perhaps four times as many chemicals to test would take indefinitely longer to characterize through scientific testing. Although EPA accelerated the rate of pesticide re-registration over the last few years to comply with FQPA mandates, whether this accelerated review has protected public health remains suspect and controversial (see Groth et al., 2001).

If we ignore the additional burdens of testing for endocrine-disrupting chemicals and replicate Congressman Synar's math exercise above, testing all potential EDCs will take over 59,000 years to complete. Unfortunately, EPA estimates that we will have to wait for years before tests are even developed for endocrine-disrupting chemicals, an inauspicious beginning to EDSP under a regulatory paradigm that fails to effectively test or regulate chemicals in most other regulatory regimes (e.g., TSCA and FQPA among others; see Montague, 1997 and Groth et al., 2001 respectively). We can also extrapolate the ultimate failure of EDSP to protect public health from precedents in the history of U.S. chemical regulation. The Toxic Substances Control Act of 1976 (TSCA, P.L. 94-469) regulates most non-pesticide, non-medical chemicals in the U.S. As of October 1996, the TSCA inventory included 75,857 chemicals (Roe et al., 1997: p. 20). EPA developed 'testing actions' requiring companies to test toxicity of chemicals currently in use (TSCA Section 4) for only 263 chemicals over the last 20 years (through 1997); only 0.35 percent of the October 1996 inventory. Over this same period, at least 20,000 new chemicals came into use. Chemical testing under TSCA proceeds so slowly that minimal toxicity information on every chemical in use could never be accumulated - more new chemicals enter the market each year than are tested for toxicity.

In 20 years (through 1997), EPA took TSCA Section 6 actions to regulate chemicals against only five chemicals or classes of chemicals. Few chemicals have been regulated under EPA authority because TSCA requires EPA to balance "unreasonable risk of injury to health or the environment" with the economic impacts of banning or regulating a chemical. In the first 20 years after passage of TSCA, EPA managed to overcome the cost-benefit test for only nine chemicals (Fagin and Lavelle, 1999). The snail's pace of chemical regulation in the U.S. pervades the entire enterprise, not just EDSP. EDSP, however, will produce new and unforeseen difficulties in scientifically determining harm.

Four principal conditions lead to the inability of EDSP to protect public health. First, the complexity of endocrine disruption prevents science from determining 
a cause and effect relationship between adverse health effects and exposure to endocrine-disrupting chemicals (see Scientfic complexity and the failure of classic toxicology subsection above). Second, there are simply too many potential endocrinedisrupting chemicals - over 87,000 . If similar U.S. chemical regulatory programs are a reliable indicator of the efficacy of EDSP, we can expect over 59,000 years of testing just to characterize this many chemicals. Third, even if the resources necessary to speed up this testing process could be obtained, the more critical issue is whether such testing could ever determine causation with sufficient certainty to merit action under current U.S. regulatory policies. Fourth, the concept of using science to determine harm before regulating any chemical is based in the scientific testing and regulation paradigm. This paradigm fails to protect public health, to account for modern social values, and to deal with the complexities and uncertainties of endocrine disruption science. Are there alternatives to such a grim situation?

\section{Alternative approaches}

As a consequence of the failure of chemical regulation in general to protect public health, a variety of alternatives to contemporary chemical regulation have been proposed. Each of these alternatives either helps reduce some health consequences of chemical exposure or improves the current state of knowledge, but each is ultimately flawed in some respects. Three popular alternatives and their limitations are examined below, and then a more promising alternative is considered that breaks from the scientific testing and regulation paradigm.

\section{Persistent organic pollutants - the Swedish alternative}

One common suggestion to improve the efficacy of pesticide regulation is to address groups of chemicals, such as persistent organic pollutants (POPs), instead of the health effects of individual chemicals. POPs are chemicals resistant to degradation in the environment. Because of their persistence, these chemicals accumulate in the atmosphere, bodies of water, and soil to high concentrations, and often further concentrate in organisms at or near the top of the food web, including humans. The persistence of POPs implicates these chemicals as sources of substantial exposure, even if the significance of that exposure remains uncertain. Restricting or banning POPs reduces environmental contamination and human exposure, but provides no information about whether those chemicals or others that are not persistent actually cause harm. For example, a study by Smith (1999) indicates that DDT in American breast milk has declined each year since 1975, shortly after the U.S. banned the substance, but science cannot determine whether trace levels of DDT in breast milk adversely affects a nursing child.

By framing the policy as an attempt to prevent the long-term accumulation and persistence of toxic chemicals, or chemicals which may become toxic given the concentrations to which they accumulate, the scientific testing and regulation paradigm is undermined. The need to scientifically prove the toxicity of an individual chemical when we cannot sufficiently establish such proof is eliminated. The POP reframing 
essentially redefines 'harm' by replacing the third assumption of the paradigm (that individual chemicals behave according to classic toxicology) with a specific definition of a group of chemicals assumed harmful. Reducing the burden of proof in this way allows for action on public health to proceed, but rests on a definition of 'harmful' chemicals that ignores all short-lived, but possibly dangerous chemicals. This strategy indirectly address health consequences by removing some of the highest exposure, and thus presumably the highest risk chemicals from the environment. The Swedish Ministry of the Environment has officially endorsed such a strategy (Chemicals Policy Committee, 1997). "The new guidelines call for banning from commerce any compound that has a half-life of more than 8 weeks in tests simulating an aqueous environment and is 2000 times more likely to accumulate in fish tissue than in seawater - a standard measure of biological uptake" (Fredholm, 2000).

Unfortunately, since a one-time low dose of some EDCs might adversely affect a developing fetus during certain stages of development, short-lived or dilute chemicals may pose as much or more of a threat than POPs. By ridding the environment of POPs, a fetus' exposure will diminish because the mother will be less likely to build up a toxic load of persistent chemicals, but pre-natal exposure to short lived chemicals will continue. Ultimately, this strategy addresses only one kind of chemical, possibly directing attention away from other dangerous non-persistent chemicals and possibly removing some safe and important chemicals from commerce. This does not mean the Swedish alternative is without merit, but it only addresses the easiest set of possible pollutants. Companies have already started phasing out persistent chemicals specifically because harm from them can be determined with relative ease:

If anything, it is becoming harder to assess exposure as persistent chemicals have been phased out in industrial countries and replaced by less persistent compounds such as methoxychlor. Like DDT, methoxychlor disrupts hormones, but unlike its predecessors, it does not leave telltale signs of exposure in body tissue (Colborn et al., 1996: p. 137).

\section{Responsibility shift}

Another popular alternative reassigns responsibility and culpability issues within the current framework of STRP. Since EPA does not have the resources to regulate an entire industry when each chemical requires extensive testing and monitoring, EPA could shift that burden to the chemical industry. Unfortunately, this might lead to significant economic consequences, not only in direct costs to chemical companies, but also in a disincentive to innovate. Safer chemicals that perform a similar task to an existing chemical might become prohibitively expensive to develop due to testing requirements. This additional expense would likely represent a more complete 'cost' of the chemical, including the costs of testing for human health effects, but this would hardly comfort those adversely affected by such a policy - chemical consumers as well as chemical companies. This representation of social or environmental costs, however, might in turn lead to innovation of healthier alternatives to chemical use for particular purposes (e.g., organic farming). Although this alternative is highly speculative, the uncertainty regarding human behavior in or outside of a marketplace 
means that any action along these lines will result in unintended consequences (Simon, 1983).

As currently practiced, industry does pay for most scientific testing of its products, but it also controls that information, and arguably the science itself (Fagin and Lavelle, 1999: chapter 3). An attempt to increase the independence of scientific testing or increase public or governmental access to that information may improve the viability and honesty of the science informing regulation. This alternative essentially accepts the necessity of scientifically proving harm before regulation, and assumes that science has the capacity to determine that harm, presumably by still using the manifestly limited models of classic toxicology. The improvement envisioned here attempts to mitigate scientific uncertainty working for industry and against public health by altering the resources available to and the control over science. This alternative, however, idealistically maintains that science can determine harm with sufficient certainty, and simplistically assumes that the only problem in chemical regulation is the need for more and better science. In other words, by leaving STRP in place, this alternative fails to address any of the structural problems with the paradigm. Nevertheless, increased public access to information and solidly placing responsibility for products on the company that profits from their creation would improve the current state of affairs, but it probably cannot moderate public health risks from endocrine-disrupting chemicals.

\section{Reduce pesticide production and use}

A third alternative involves reducing pesticide use to improve the relevant public health outcomes. Several U.S. government studies suggest this option (NAS, 1993a; OTA, 1991; U.S. GAO, 2001). By reducing the volume of chemicals released into the environment, exposure to chemicals diminishes. Sweden, Denmark, the Netherlands, and the Canadian province of Ontario all adopted this approach with varying levels of success. The Swedish program reduced the mass of pesticides used by 50 percent between 1986 and 1991 (WWF, 1992). According to a 1998 report, pesticide use in Sweden in 1998 was $55 \%$ of the average from 1984 to 1988 (Fogelberg, 2001). The Danish program achieved a 25 percent reduction between 1986 and 1990 (Olson et al., 1995; WWF, 1992). Notably, agricultural yield did not crash as a result of these policies. Farmers can accomplish a massive reduction in pesticide use by re-instituting pest-resistant farming practices, such as crop rotation, which prevent disease from spreading rapidly. Estimates put the increased cost of production of using such farming practices at $\$ 10$ per hectare ${ }^{13}$ (Pimentel et al., 1991). This alternative avoids goal substitution by focusing on the end goal, to protect public health, and ignoring the instrumental goal, to use science. This alternative operates on the assumption that reducing the total amount of pesticides released into the environment reduces risk to public health.

Another option to reduce pesticide exposure without falling into the trap of STRP by regulating their use is the promotion of alternatives to pesticide use. Increased government subsidies for organic farming would go a long way toward reducing pesticide volumes used each year without the potential adverse political and economic effects of regulating farming practices or the chemical industry. The National Organic 
Program of the U.S. Department of Agriculture (USDA) indicates the potential of such strategies, but political support and momentum for government promotion and encouragement of organic meat and produce is limited at best (National Organic Program, 2002).

The use of pesticides sometimes causes farmers to lose money. USDA found that farmers often apply pesticides when not needed or in greater quantities than required. This means that farmers sometimes waste money by applying pesticides and would benefit economically from reduced pesticide use, even considering all anticipated damage to crops (Pimentel et al., 1991). Alternatives to pesticide use, however, are rarely considered, even when it is in the economic interests of farmers. Integrated pest control techniques, including surveillance, economic analysis, and focused pesticide application, in addition to alternatives such as organic farming, rarely make it into the official agenda and government promotes such common sense alternatives poorly (NAS, 1989; Curtis, 1991; U.S. GAO, 2001). Evidence also suggests that pesticide use actually leads to increased crop damage and thus increased costs to farmers by killing off insects that prey on crop pests, by allowing crop pests to develop resistance to pesticides, and by encouraging unsustainable farming practices (Carson, 1962; Osteen and Kuch, 1986; Pimentel et al., 1991).

The pesticide reduction alterative presents the most promising alternative so far. Reducing pesticide use reduces pesticide contamination and consequent exposure, thus mitigating the health consequences of many chemicals pollutants. However, endocrine specific effects do not necessarily diminish with decreasing exposure as two of the assumptions of classic toxicology assert - monotonic dose-response and threshold effect. This means that endocrine disruption would likely continue, perhaps diminished, but maybe not - perhaps even magnified in some instances. In other words, the trap of the scientific testing and regulation paradigm has been subverted only by avoiding regulation entirely. In some cases, however, regulation of certain chemicals will remain the only possible way of protecting public health. While avoiding goal substitution brings many neglected alternatives for improving public health outcomes to the focus of attention, it does not address the flaws that prevent regulation of harmful chemicals under STRP. Reducing pesticide use is not a bad idea, just an incomplete one for dealing with EDCs. If society feels that protecting public health, especially young and unborn children, from endocrine-disrupting effects is important, a better regulatory strategy is also needed.

\section{The Waxman alternative}

For a policy to address public health risks from EDCs, it must break free of the assumptions of STRP. Legislation proposed at the same time as FQPA in the U.S. House of Representatives provides an example of how this might be accomplished. Representative Henry Waxman introduced a bill (the Pesticide Safety and Right-toknow Act of 1995, H.R. 1771) with substantially more emphasis on public health than FQPA. The bill employed consumer right-to-know strategies, addressing the end goal of protecting public health through an instrument other than science. But more importantly, the bill explicitly rejects the assumptions of the scientific testing and regulation paradigm. The bill required the EPA Administrator to: 
[D]etermine in writing whether dietary exposure to the pesticide chemical... is reasonably anticipated to cause cancer, damage to the developing neurological, immune, or reproductive systems, or other serious adverse health effects in any child.... The [EPA] Administrator may not prescribe a tolerance for a pesticide chemical if the Administrator determines that dietary exposure to the pesticide chemical under such a tolerance is reasonably anticipated to cause such effects in any child.

This language moves beyond the scientific testing and regulation paradigm. Recall the partial list of assumptions of the paradigm: (1) scientific determination of harm must precede regulatory action, (2) science has the capacity to determine harm with sufficient certainty, and (3) chemical exposure affects humans according to the assumptions of classic toxicology. The Waxman alternative moderates the dysfunctional consequences of assumption one because the bill mandates action to protect public health before allowing a chemical to go to market, thus explicitly preventing chemical release before or during a determination of health consequences. Assumption two is moot because adverse effects don't have to be proved with certainty, only "anticipated." The 'anticipate' concept is crucial because it reconceptualizes the relevance of science by throwing out the search for an unattainable legal or scientific 'certainty' and replacing it with something along the lines of 'the best available knowledge.' 14 Additionally, since the Waxman alternative places public health at the center of the regulatory agenda, the scientific assumptions of classic toxicology (assumption three) no longer promote goal displacement by attempting to make progress in terms of the instrumental goal independent from the end goal to protect public health.

This bill could, however, result in reversal of the outcome gridlock by banning all chemicals until proven safe. Waxman's language suggests this possibility by prohibiting any chemical anticipated to adversely affect "any child" (emphasis added). Simply reversing assumption one of the paradigm from, essentially, a chemical is innocent until proven guilty (an economic freedom principle) to a chemical is guilty until proven innocent (a precautionary principle) does not address the root problem.

Focusing exclusively on this fault in Waxman's proposal, however, counterproductively avoids dealing with the real problem - the dysfunctional relationship between science and policy. The creative aspect of Waxman's proposal is the eminently practical reconceptualization of the role science can and should play in decisions about public health in chemical regulation. Any rational policy alternative must make tradeoffs when dealing with possibly dangerous chemicals that also provide a valuable function in society. Remove the word "any" before child in the text of Waxman's proposal, and we have an example of policy design that breaks out of the STRP deadlock.

\section{The risk analysis precedent}

Calling for a change in the role of science in decision-making may seem to some impractical. However, recent discussion and debate in the risk analysis literature indicates just such a change is occurring. Some discussion and debate about risk has many similarities to the issues raised in this study - high levels of uncertainty, the relevance of public concerns, the legitimate role of normative considerations, etc. 
Klinke and Renn describe risk-based versus precaution-based strategies:

With the denotation of "risk" it becomes clear that management relies on the numerical assessment of probabilities and potential damages, while the denotation of "precaution" implies prudent handling of uncertain or highly vulnerable situations. ... To nobody's surprise, environmental groups have rallied around the precautionary approach, while most industrial and commercial groups have been fighting for the risk-based approach (Klinke and Renn, 2002: pp. 1074-1075).

This debate between risk- and precaution-based approaches parallels the issues involved with the first claim of STRP: scientific determination of harm must precede regulatory action. Industry, to nobody's surprise, clings to this ideal that a chemical is 'innocent until proven guilty,' while many public health and environmental interests would like to see that formula changed to a chemical is 'guilty until proven innocent.' Both perspectives incorporate scientific proof as the necessary condition for restriction or distribution of a chemical respectively. But neither perspective addresses the shortcomings of science itself as a guide for decision-making, and the consequent inability to meet the strict demands of proof and evidence under either assumption. If we recognize the limitations of science in such a situation, neither perspective provides a reasonable alternative for a common interest strategy to protect public health.

Klinke and Renn suggest some strategies to consider in situations (like endocrine disruption) of uncertainty both about the severity of the effects and the probability of its occurrence. They claim that under such conditions, coping with uncertainties is a prudent course. "Rather than investing all efforts to gain more knowledge about the different components of uncertainty, one can try to develop better ways to live or co-exist with uncertainties and ignorance. The new key words here are: resilience, vulnerability management, robust response strategies, and similar concepts" (Klinke and Renn, 2002: p. 1074). Such strategies must integrate social, economic, psychological, and other factors with scientific factors when determining a best course of action (Stern and Fineberg, 1996). Klinke and Renn suggest the following 'management tools' for dealing with highly uncertain risks: containment of application in space and time, constant monitoring of potential side effects, development of functional equivalents with less persistent or ubiquitous consequences, promoting diversity and flexibility, capacity building for organizational competence, building high-reliability organizations for handling uncertain risks, introduction of strict liability, and classic tools such as ALARA (as low as reasonably achievable), BACT (best available control technology), etc. The field of risk analysis, in other words, has explicitly acknowledged that scientific determination of risk alone is insufficient to address complex, uncertain, and ambiguous problems.

\section{The EDSP decision process}

FQPA updated and clarified two older laws that presented "a mishmash of competing and conflicting standards" for the regulation of pesticides and pesticide exposure 
through food (Kasindorf, 1993). These two acts were the Federal Food Drug and Cosmetic Act (FFDCA, P.L. 75-717) and the Federal Insecticide, Fungicide, and Rodenticide Act (FIFRA, P.L. 80-104). The last major reform of FIFRA occurred in 1972 when the newly formed EPA was given authority to enforce regulation (P.L. 92$387)^{15}$ while FFDCA had not been meaningfully reformed since the Food Additives Amendment of 1958 (P.L. 85-929). The delay between the last major reform of these laws and FQPA (24 and 38 years, respectively) does not indicate broad satisfaction with the legislation; in fact, almost nobody was satisfied with the laws. ${ }^{16}$ The delay in reform indicates the intensity and divergence of interests concerned with pesticide legislation, and an inability of competing interests to agree upon a mutually acceptable policy alternative.

The unanimous passage ${ }^{17}$ of FQPA in 1996 broke a decade-long deadlock over pesticide reform and consummated two decades of effort to clarify and update FIFRA and FFDCA. FQPA achieved this political success because stakeholder groups on all sides of the pesticide issue felt that their concerns were addressed by the legislation. Replacement of the long-standing balance of risk and benefits criterion with a new explicitly health-based criterion wooed environmental and public health groups. ${ }^{18}$ The mandate to screen for EDCs and stricter standards for pesticides in food for children won the bill additional praise from environmental, labor, consumer, and public health interests. On the other side of the table, chemical industry and farmer groups approved scrapping the Delaney Clause in the 1958 Food Additive Amendments to FFDCA, replacing the prevailing and litigation-tested "zero-risk" standard with a more economically viable "reasonable certainty of no harm" standard. ${ }^{19}$ The bill also prevented states from adopting more stringent standards than EPA for pesticide chemicals, addressing industry and business group concerns (Schierow, 1996; Groth et al., 2001).

The decade leading up to passage of FQPA and its mandate to test for endocrinedisrupting chemicals demonstrated increasing public and governmental concern over the effects of pesticides in the food supply. Government and environmental groups released several scientific reports in the late 1980s and early 1990s. Following a National Research Council report (NRC, 1987), the Natural Resources Defense Council (NRDC) released the most visible report in February 1989, titled Intolerable Risk: Pesticides in our Children's Food - bringing the issue of pesticide health risks to public attention (NRDC, 1989). A 60 minutes report aired on February 26 of that year motivated by this report and its findings, giving the issue national media attention (CBS-TV, 1989). The show led to the now infamous 'Alar scare' which caused a drop in the sale of apples and apple products in the following years because of the purported adverse health effects of the chemical Alar, used to make the crop ripen uniformly on the tree (Associated Press, 1990).

Following the NRC report, Congress commissioned another report from the National Academy of Sciences (NAS) in 1988. This report was delivered three years overdue on June 27, 1993, and titled 'Pesticides in the Diets of Infants and Children' (NAS, 1993b). The Environmental Working Group released an in-house study on pesticides one business day before the NAS report (Wiles and Campbell, 1993). All of these reports indicated that public health remained at risk from pesticides, particularly the health of children. These reports, at least circumspectly, also indicated that 
the then current regulatory regime of FFDCA and FIFRA failed to protect children and public health.

During the same period, the U.S. Supreme Court rejected a petition by the National Agricultural Chemical Association to take up a case challenging the zero-risk standard of the Delaney Clause. The Supreme Court's rejection meant that a unanimous 9th Circuit Court of Appeals ruling in July 1992 mandating strict enforcement of the Delaney Clause stood (U.S. 9th Circuit Court, 1992). Additionally, a lawsuit initiated in 1989 by several environmental groups alleging that EPA violated the Delaney Clause settled in February 1995 in the People of the State of California v. Browner consent agreement (U.S. District Court, 1995). According to the Congressional Research Service (CRS), "[u]nder provisions of the agreement, entered as a consent decree enforceable by the court, EPA will be required to set policy that could lead to cancellation of about 10 percent of specific uses of 37 pesticides. A single use is assigned a specific pesticide/food combination. Some uses of roughly 40 other pesticides may also be affected" (CRS, 1996).

The increased visibility of the pesticide issue along with the exhaustion of legal alternatives to enforcing the Delaney Clause and election year politics led to the sweeping passage of FQPA. The combined effect of these studies with associated media coverage and public outcry and the 1992 court decision led the Clinton White House to propose pesticide reform in 1994 (Pesticide Reform Act, H.R. 4362) ${ }^{20}$ The 1995 California vs. Browner consent agreement almost certainly helped encourage the unanimous passage of FQPA in 1996. What this story obscures, however, is the contention in Congress over pesticide reform. The bill that passed in the House as FQPA on July 23, 1996 barely resembled the bill known as FQPA on July 10, when negotiations began to revise it.

Representatives Thomas Bliley and Richard Lehman first introduced H.R. 1627, FQPA, in 1993 with 225 cosponsors. In the next Congress, FQPA gained five more cosponsors with some revision. According to Representative Waxman's website:

Instead of improving the law to protect infants and children as recommended by the National Academy of Sciences, H.R. 1627 [FQPA before July 17] would have weakened even the marginal protection offered by existing pesticide laws. H.R. 1627 would have replaced the Delaney Clause with a significantly weaker standard and opened new substantive and procedural loopholes. The bill would have allowed even the most dangerous pesticides to legally remain in use (Waxman, 2002).

Environmental groups adamantly opposed this version of FQPA. For example, Caroline Dewaal with the Center for Science in the Public Interest (1995) testified:

The Food Quality Protection Act, HR 1627, is legislation that is headed in the wrong direction. HR 1627 will likely increase the presence of toxic pesticide residues in the food supply. It ignores the fact that conventional testing protocols cannot always identify long-term health risks associated with pesticide use, while studies can always be produced to show short-term economic loss, whether real or imagined. HR 1627 puts the health of corporations before the health of children. 
And Ed Hopkins of Citizen Action (1995) testified:

If congress enacts H.R. 1627, it will make an already inadequate pesticide regulatory system worse. A combination of fundamental policy changes would weaken current standards and allow more pesticides in the food supply, increasing risks of cancer, birth defects, and damage to the neurological and immune systems.

As the Commerce Committee neared formal consideration of FQPA, Rep. Waxman, Chairman Bliley, and Rep. Dingell began discussions on July 10 to resolve their differences on pesticide reform. With incredible speed, they reached an agreement on July 14, which they substituted for the original FQPA on July 17. The Health and Environment Subcommittee and subsequently the Commerce Committee unanimously approved the Waxman-Bliley-Dingell agreement. Unanimous passage in the House on July 23 sent FQPA to the Senate and President Clinton's desk (Waxman, 2002). Most public health and environmental interest groups and industry endorsed this revised version of FQPA.

But why did environmental and public health organizations support this bill if, as argued in this study, it could never protect public health? First, these interest groups misperceived the Waxman-Bliley-Digell agreement as a victory for public and environmental health. Although this victory did not give environmental and public health groups the legislation they wanted, it prevented an even bigger perceived loss. Considering that 230 representatives cosigned legislation widely viewed as a catastrophe for public health (FQPA before July 17, 1996), one can easily imagine the sense of relief that environmental and public health interest groups must have felt following the Waxman-Bliley-Dingell agreement. In fact, imagination is unnecessary. Most of the major interest groups officially endorsed the legislation, and the congressional vote was unanimous! The following public health and environmental interest groups officially supported FQPA: American Preventative Medical Association, American Public Health Association, Center for Science in the Public Interest, Citizen Action, the Environmental Defense Fund, the Environmental Working Group, the National Audubon Society, the National Parent Teacher Association, the National Wildlife Federation, the Natural Resources Defense Council, Physicians for Social Responsibility, Public Voice, and World Wildlife Fund - most of the major players promoting pesticide regulatory reform.

In terms of public health this provided, at best, a hollow victory, and at worst, a critical lapse which removed pesticide reform from public attention for years to come while making little or no headway in protecting public health. ${ }^{21}$ Critical lapse seems closer to reality in this situation. The passage of FQPA, and especially the enthusiastic support of environmental and public health interest groups gave the impression that the public health threat of chemical contamination from pesticides had been addressed. As subsequent experience demonstrates, the threat continues and FQPA and EDSP are unlikely to significantly moderate the public health risks. In other words, instead of solving the perceived problem, Congress created legislation that made only superficial changes to the pesticide regulatory system and created EDSP, a program good at doing science, but ineffective at protecting public health. 
Second, in addition to averting perceived catastrophe, environmental and public health interest groups still bought into the scientific testing and regulation paradigm, at least partially. Before the compromise, environmental and public health groups clearly supported the strategy encompassed in Rep. Waxman's alternative. This indicates that the environmental and public health interest groups had at least a vague idea of the superiority of the Waxman alternative. Again, from the testimony of Ed Hopkins of Citizen Action (1995):

In our view, H.R. 1771 [the Waxman alternative] provides a more certain route [than H.R. 1627 before July 17] to protecting the health of infants and children. It specifically requires EPA to implement the recommendations of the NAS report. This more specific direction will be extremely important when litigation arises over a tolerance EPA sets to protect children. ... H.R. 1771 also requires EPA to make a specific finding as to whether a pesticide tolerance is "reasonably anticipated" to cause adverse health effects in children and, if it is, requires that EPA may not prescribe that tolerance. Again, that strengthens EPA's ability to set adequate tolerances and builds in public accountability that the Agency is actually setting adequate tolerances.

However, most environmental and public health interest groups officially endorsed the Waxman-Bliley-Dingell agreement. A few public interest groups opposed FQPA, but their reasons are hardly compelling. According to a Washington Post analysis, the U.S. Public Interest Research Group opposed the clause that bars states from passing their own more stringent food safety standards, and one environmental group felt it important to retain the Delaney Clause. "By establishing an absolute ban against all potential carcinogens, the [Delaney Clause] provision served as an important weapon in the war against cancer, said Jay Feldman, executive director of the National Campaign Against the Misuse of Pesticides" (Lee, 1996). Neither the issue of states' rights nor Feldman's unwillingness to compromise on an absolutist element of outdated chemical policy inspired new alternatives to a failing regulatory paradigm. Seemingly, no interest group provided a sound, creative, or compelling critique of FQPA or, subsequently, EDSP. Why?

None of the participants seemed to understand the reasons that chemical regulation has historically failed to protect public health in the United States. ${ }^{22}$ Although many environmental and public health interest groups seemed to understand the superiority of the Waxman alternative, they failed to understand the significance of supporting the post-compromise FQPA. Because of the lack of creative alternatives, and the near universal support of the major proponents of reform, these interest groups seem to have honestly felt they were supporting an alternative that would improve public health. Unfortunately, this also indicates these interest groups did not understand the extent to which the assumptions of the scientific testing and regulation paradigm prejudice attempts to regulate chemicals.

Because the major proponents of reform failed to promote a policy that improves public health outcomes, this paradigm seems to present a major impediment to better chemical regulatory policy design. This also suggests a concrete way to affect change. A variety of participants continue to fight for public health driven chemical regulation 
in a paradigm that unfairly favors industry. The framing of the problem precludes certain options from being considered and lends some alternatives weight beyond their merit when viewed from outside the conceptual box of STRP. An increased awareness of the limitations placed upon chemical regulation by this framing would benefit environmental and public health interest groups as well as sympathetic members of Congress, EPA, industry, media, the public, and the scientific community by clarifying the importance of the basic assumptions of different strategies.

For example, the Waxman alternative, H.R. 1771, broke out of the historical framing of pesticide regulation by preventing chemical release before determining health risk, concentrating on public health, and explicitly reconceptualizing the role of science in regulation. If environmental and public health interest groups and other sympathetic participants appreciated the functional benefits of this reframing of the problem, they could make more informed decisions about compromise on pesticide and endocrine-disrupting legislation in the future.

\section{Conclusions}

The Endocrine Disruptor Screening Program is doomed to failure with respect to protecting public health due, most importantly, to the assumptions of the scientific testing and regulation paradigm. Among the assumptions of this paradigm are: (1) scientific determination of harm must precede regulatory action, (2) science has the capacity to determine harm with sufficient certainty, and (3) chemical exposure affects humans according to the assumptions of classic toxicology. This paradigm has two major effects on attempts to protect public health from endocrine-disrupting (and other) chemicals.

First, acceptance of this frame narrows the focus of attention to 'getting the science right.' This promotes goal substitution by emphasizing the instrumental goal - to use science - at the expense of the mandated end goal - to protect public health. Congress mandated both goals, but prioritized the instrumental goal in FQPA, a logical consequence of STRP buy-in by decision makers. Even environmental and public health interest groups formally endorsed FQPA, further illustrating that STRP is taken for granted, even by those it most impairs. In other words, the constitutive decision process, suffused with the assumptions of STRP, is a crucial factor conditioning the failure of EDSP. Without reformulating the constitutive paradigm, public health outcomes are unlikely to improve significantly. This focus on 'getting the science right' undermines the end goal to protect public health by distracting attention and other resources from non-testing regulatory alternatives (e.g., mandated pesticide use reduction), and non-regulatory alternatives (e.g., subsidies for organic farming) even in the face of an ineffective regulatory regime.

There is, however, a second issue at hand: some regulation is necessary. As the science of endocrine disruption indicates, substantial uncertainty and complexity plague our knowledge of endocrine-disrupting chemicals. Attempts to establish statistically significant cause and effect relationships between chemicals and health risk typically fail. But lower dose exposure to some endocrine-disrupting chemicals actually increases the health consequences of exposure, and exposure to minute concentrations during certain stages of fetal development can be harmful, even deadly. Simply 
reducing chemical exposure cannot protect public health from some chemicals regulation is a necessary component of the solution.

The complexity of endocrine disruption and additional complexity from social and environmental factors associated with exposure almost guarantees our inability to scientifically or legally prove harm. But if we are still to protect public health, we must find a way to deal with these chemicals by reconceptualizing what constitutes sufficient proof. This implies a need to redefine the appropriate relationship of science to endocrine disruption regulation. We must pragmatically assess the capabilities of modern science, and bring our expectations of science in line with reality. If harm cannot be proven under current criteria, perhaps we must use different criteria, such as a 'preponderance of evidence.' Scientific uncertainty should not work for industry and against public health by default (the current situation), but neither should it work by default the other way around (a precautionary principle). To regulate chemicals rationally, both to protect public health and to allow useful and important chemicals to market, the role of science in making decisions about chemical regulation must be revised.

Failing to question the first assumption of STRP, that scientific determination of harm must precede regulatory action, leads to goal substitution by focusing on 'getting the science right.' Uncritical acceptance of the second assumption, that science has the capacity to determine harm with sufficient certainty, leads to an impoverished and ineffective conception of the role of science in regulating endocrine disruptors. Both of these errors involve untenable assumptions at the constitutive level. But errors such as these are increasingly recognized in a variety of fields such as risk analysis (e.g., Stern and Fineberg, 1996) and natural resource management (e.g., Gunderson et al., 1995). Some frequently proposed solutions in these and other literatures worthy of consideration in this context include: redundancy, resilience, adaptive management, public participation, coping with uncertainties, and no regrets policies. Some combination of such strategies will likely prove necessary for dealing with the uncertainty, complexity, and ambiguity of endocrine disruption.

\section{Acknowledgements}

This material is based on work supported under a National Science Foundation Graduate Research Fellowship. My thanks to Ronald D. Brunner, Roger A. Pielke, Jr., and David O. Norris for their many improvements on my ideas and writing. I also owe a debt to Marilyn Averill, Richard and Idell Vogel, David Pelletier, and two anonymous reviewers. Of course, I reserve exclusive bragging rights for all errors, mistakes, blunders, and oversights in this study.

\section{Notes}

1. An acute health effect involves immediate consequences of exposure such as consumption of rat poison causing violent illness or death. A chronic health effect occurs from low-level exposure to a substance over time, such as household use of a pesticide over months or years leading to cancer.

2. Active ingredients are the chemical(s) in the pesticide known to kill pests. Many other chemicals with no pesticide effect are added to the active ingredient to make the chemical easier to distribute 
or use. Actual U.S. release of pesticides including 'inactive ingredients' in 1999 was approximately 5 billion pounds (Donaldson et al., 2002). There are no guarantees that the 'inactive ingredients' do not have toxic or endocrine-disrupting effects on humans or other wildlife. They are called inactive only because they do not kill pests.

3. Other sources of potential exposure ignored in this article include: hormones in meat and milk, chemical treatment of wastewater, non-point source pollution, residuals from rocket fuel, agricultural run-off, chemical treatments such as fire retardants on clothing or furniture, fumes from gasoline, and others. Natural EDCs are also excluded because the existence or magnitude of exposure to such compounds is irrelevant to the purpose of this paper, namely, analyzing the relationship between science and policy as a factor conditioning the failure of EDSP.

4. Congress passed the Pure-Food Act, also known as the Federal Food and Drugs Act (later called the Federal Food, Drug, and Cosmetic Act (FFDCA)) in 1906 and the Insecticide Act in 1910. The Federal Insecticide, Fungicide, and Rodenticide Act (FIFRA) replaced the Insecticide Act in 1947.

5. For clarity, let me emphasize that the scientific testing and regulation paradigm is a macro-scale concept. It does not necessarily describe the action of EPA ground-level personnel in specific cases of regulatory decision-making. The paradigm does, however, describe the assumptions at the broader prescriptive level that formally, and often effectively, limit the scope of appropriate action by implementing agencies and personnel.

6. The term 'sufficient' in reference to certainty highlights the subjective nature of certainty in regulation. Required certainty is determined either by law or subjective value judgments. Science alone cannot determine what kind or what level of certainty is required - or for whom, or for what purpose, or by what standard, etc. See note 19 for an example of a legal definition for the required level of certainty under FQPA.

7. DES and thalidomide are both endocrine-disrupting chemicals. Although capitalizing on the public horror associated with these chemicals might strengthen my argument, I have chosen not to discuss these chemicals at length because they were not pesticides.

8. Most of the synthetic endocrine-disrupting chemicals discovered to date pass freely across the placental barrier (e.g., see Miyakoda et al., 1999).

9. Some hormones and most hormone receptor sites are protein molecules. They have a primary structure: sequence of amino acids; secondary structure: three-dimensional folding of the amino acid sequence; tertiary structure: three-dimensional folding of the secondary structures; and sometimes a quaternary structure: the interaction of multiple tertiary structures composed of separate primary polypeptide chains. Others are polypeptides - similar chemicals lacking quaternary structure, and usually less than 100 amino acid molecules long.

10. For a related discussion on the assumptions of classic toxicology, approached from a different perspective, see a recent article by Calabrese and Baldwin (2003).

11. For purposes of this paper, FQPA refers to the combined legislation mandating testing for endocrine effects, both to the Food Quality Protection Act of 1996 and to the Safe Drinkig Water Act Amendments of 1996. This shorthand necessarily introduces some inaccuracy, but the abbreviation substantially increases the clarity of this study.

12. As of July 2004 no screening or testing procedures have been validated.

13. A hectare is a metric unit equivalent to 10,000 square meters, or approximately 2.5 acres.

14. Although in 'anticipating' human health effects, EPA would likely use scientific methods, the issue at hand is not that science in inappropriate for use in this context, but that the assumptions about science and policy embedded in the scientific testing and regulation paradigm are inappropriate. Whether this language is sufficient to undermine STRP and reorient science is debatable, but it is necessary.

15. Some people argue that a law passed in 1978 amounted to a major reform of FIFRA (Waxman, 2002). The choice of date is unimportant and either will serve to make the consequent point adequately.

16. Environmental and public health interest groups felt that risks to public health existed under the then current regulatory framework while industry feared rigid application of the Delaney Clause.

17. No dissenting votes were cast in either house of Congress. The House passed FQPA 417-0 and the Senate passed the House version by unanimous consent.

18. The risk and benefits criterion required that EPA consider the economic effects of banning a pesticide before taking any regulatory action. In other words, public health and company profits were formally on an even playing field, a situation objectionable to many environmental and public health interest groups. 
FQPA allowed some consideration of economic effects, but only under carefully crafted circumstances that restricted the importance of economic effects considerably.

19. Although EPA rarely invoked the Delaney Clause, industry groups felt it as a looming threat to established pesticide practices, a threat which intensified due to court action requiring enforcement. Delaney required "zero cancer risk" from additives or residual pesticides in processed foods only (fresh foods were not covered by Delaney). The "reasonable certainty of no harm" standard promulgated in FQPA means a 95\% probability that one additional cancer or less will occur among one million people exposed at that level over a lifetime.

20. Rep. Waxman introduced H.R. 4362 for President Clinton. Waxman had already introduced a more restrictive resolution almost two months earlier, the Pesticide Food Safety Act of 1994 (H.R. 4091), with provisions to "[p]rohibit the issuance of a tolerance for any pesticide that contains an active or inert ingredient that is a known or probable human carcinogen or highly hazardous to human health" (Pesticide Food Safety Act, H.R. 4091).

21. This is known as a political catharsis (Lasswell and Kaplan, 1950: p. 9). The intensity of the public's demand for action diminished without a corresponding change in the reasons for the public's initial outrage.

22. In addition to this study, see Groth et al., 2001; Fagin and Lavelle, 1999; Montague, 1997; and Roe et al., 1997, for some evidence of the failure of chemical regulation in various incarnations.

\section{References}

Associated Press (1990). 'After scare, suit by apple farmers', The New York Times, Late Edition - Final, A22, November 29.

Aspelin, A. L. (1994). Pesticide Industry Sales and Usage: 1992 and 1993 Market Estimates. Washington, DC: EPA, June.

Bern, H. A., P. Blair, S. Brasseur, et al. (1991). The Wingspread Consensus Statement. 'Chemicallyinduced alterations in sexual development: The wildlife/human connection', Appendix in T. Colborn, D. Dumanoski and J. P. Myers (eds.) (1996). Our Stolen Future: Are We Threatening our Fertility, Intelligence, and Survival? - A Scientific Detective Story. New York: Penguin Books.

Birnbaum, L. S. (1995) 'Developmental effects of dioxin', Environmental Health Perspectives Supplement 7, 103: 89-94.

Burlington, H. and V. F. Lindeman (1950). 'Effect of DDT on testes and secondary sex characteristics of white leghorn cockerels', Proceedings of the Society for Experimental Biology and Medicine. 74: 4851.

Calabrese, E. J. and L. A. Baldwin (2003). 'Toxicology rethinks its central belief: Hormesis demands a reappraisal of the way risks are assessed', Nature (421), February 13, 691-692.

Carson, R. (1962). Silent Spring. Boston: Houghton Mifflin Company.

Cavieres, M. F., J. Jaeger and W. Porter. 2002. 'Developmental toxicity of a commercial herbicide mixture in mice: I. Effects on embryo implantation and litter size', Environmental Health Perspectives 110: 1081-1085.

CBS-TV (1989). 'A is for apple', 60 Minutes. February 26.

Chemicals Policy Committee (1997). Towards a Sustainable Chemicals Policy. Ministry of the Environment, Stockholm, Sweden: Government Official Reports 1997:84.

Colborn, T., A. Davidson, S. N. Green et al. (1990). Great Lakes, Great Legacy? Washington, DC: Conservation Foundation.

Colborn, T., D. Dumanoski and J. P. Myers (1996). Our Stolen Future: Are We Threatening our Fertility, Intelligence, and Survival? - A Scientific Detective Story. New York: Penguin Books.

CRS (1996). Environmental Protection Agency FY 1996. Appropriations: Analyses of House-Passed Riders. 95-966 ENR.

Curtis, J. et al. (1991). Harvest of Hope: The Potential for Alternative Agriculture to Reduce Pesticide Use. Natural Resources Defense Council. May.

Dewaal, C. S. (1995). Center for Science in the Public Interest. Congressional Testimony to House Commerce Committee, Subcommittee on Health and Environment. Hearings on H.R. 1627. June 29. 
Donaldson, D., T. Kiely and A. Grube (2002). Pesticide industry sales and usage:1998 and 1999 market estimates. Washington, DC: EPA, August. http://www.epa.gov/oppbead1/ pestsales/99pestsales/market_ estimates1999.pdf.

EPA (2002). Report to the U. S. House of Representatives Committee on Appropriations on the Status of the Endocrine Disruptor Methods Validation Subcommittee. March.

EPA (2003a). Endocrine Disruptor Screening Program Web Site. http://www.epa.gov/ scipoly/oscpendo/index.htm.

EPA (2003b). Priority Setting in the EDSP. http://www.epa.gov/scipoly/oscpendo/prioritysetting/index. htm.

Fagin, D. and Marianne, L. (1999). Toxic Deception: How the Chemical Industry Manipulates Science, Bends the Law, and Endangers Your Health. Monroe, Maine: Common Courage Press.

'Federal Food Drug and Cosmetic Act' (1938). Public Law 75-717, Cong. Ch. 675, 52 Stat. 1040, June 25.

'Federal Insecticide, Fungicide, and Rodenticide Act' (1947). Public Law 80-104; Cong. Ch. 125, 61 Stat. 163 , June 25

Fogelberg, F. (2001). 'Research on pest control and pesticide reduction in Sweden, Denmark and the Netherlands - Ongoing work and new ideas for the future', Department of Agricultural Engineering, Swedish University of Agricultural Sciences.

'Food Additives Amendment of 1958' (1958). Public Law 85-929, H.R. 13254, 72 Stat. 1784, Sept 6.

'Food Quality Protection Act of 1996' (1996). Public Law 104-170, HR 1627, 110 Stat. 1489, August 3.

Fredholm, L. (2000). 'Chemical testing: Sweden to get tough on lingering compounds', Science 290(5497): 1663-1666.

Groth, E. III, C. M. Benbrook, K. L. Benbrook and A. J. Goldberg (2001). 'A report card for the EPA successes and failures in implementing the Food Quality Protection Act', Consumers Union of the United States. February.

Gunderson, L. H., C. S. Holling and S. S. Light (eds.) (1995). Barriers and Bridges to the Renewal of Ecosystems and Institutions. New York: Columbia University Press.

Hemond, H. F. and E. J. Fechner (1994). Chemical Fate and Transport in the Environment. San Diego: Academic Press.

Hopkins, E. (1995). Citizen Action. Congressional Testimony to House Commerce Committee, Subcommittee on Health and Environment. Hearings on H.R. 1627. June 29.

Howdeshell, K. (2002). 'A model of the development of the brain as a construct of the thyroid system', Environmental Health Perspectives. 110: 337-348.

'Insecticide Act of 1910' (1910). Public Law 61-152; Cong. Ch. 191; 36 Stat. 331, April 26.

Kasindorf, M. (1993). 'Bugging out? Clinton administration proposes new rules on pesticides' Newsday, City Edition, News 8, September 22.

Klinke, A. and O. Renn (2002). 'A New Approach to Risk Evaluation and Management: Risk-Based, Precaution-Based, and Discourse-Based Strategies', Risk Analysis 22: 1071-1094.

Krimsky, S. (2000). Hormonal Chaos: The Scientific and Social Origins of the Environmental Endocrine Hypothesis. Baltimore: Johns Hopkins University Press.

Lasswell, H. D. and A. Kaplan (1950). Power and Society: A Framework for Political Inquiry. New Haven: Yale University Press.

Lee, G. (1996). 'In food safety changes, victories for many', The Washington Post.

McLachlan, J. A. (ed.) (1980). Estrogens in the Environment. New York: Elsevier North-Holland.

McLachlan, J. A. (ed.) (1985). Estrogens in the Environment II: Influences on Development. New York: Elsevier North-Holland.

McLachlan, J. A. and S. F. Arnold (1996). 'Environmental estrogens', American Scientist 84: 452-461.

McLachlan, J. A. and R. R. Newbold (1987). 'Estrogens and development', Environmental Health Perspectives $75: 25-2$.

Miyakoda, H., M. Tabata, S. Onodera and K. Takeda (1999). 'Passage of bisphenol A into the fetus of the pregnant rat', Journal of Health Science 45(6): 318-323.

Montague, P. (1997). 'The Toxic Substances Control Act', Rachel's Environment and Health Weekly, September 18 .

Myers, J. P. (2003). Our Stolen Future http://www.ourstolenfuture.org/. 
National Academy of Science (1993a). Soil and Water Quality: An Agenda for Agriculture. Washington, DC: National Academy Press.

National Academy of Science (1993b). Pesticides in the Diets of Infants and Children. Washington, DC: National Academy Press.

National Academy of Science (1989). Alternative Agriculture. Washington, DC: National Academy Press.

National Toxicology Program (2001). 'Endocrine disruptors low dose peer review'. National Institute of Environmental Health Sciences, National Institutes of Health. August. http://ntpserver.niehs.nih.gov/htdocs/liason/LowDosePeerFinalRpt.pdf.

National Organic Program (2002). http://www.ams.usda.gov/nop/.

National Research Council (1987). Regulating Pesticides in Food: The Delaney Paradox. Washington, DC: National Academy Press.

Natural Resources Defense Council (1989). Intolerable Risk: Pesticides in Our Children's Food, February.

Office of Technology Assessment (1991). Beneath the Bottom Line: Agricultural Approaches to Reduce Agrichemical Contamination of Groundwater. Washington, DC: U.S. Government Printing Office.

Olson, E., M. Wall, A. Martin, R. M. Gould, M. Cummings Hubbard, M. Moore, M. Undem and T. Olle (2002). Letter to EPA, Re: Settlement agreement to protect the health of children and farm workers under the Food Quality Protection Act in NRDC et al. v. EPA, No. C-99-3701CAL (N.D. Cal). October 23.

Olson, E., A. Meyerhoff and J. Curtis (1995). Natural Resources Defense Council. Congressional Testimony to House Commerce Committee, Subcommittee on Health and Environment. Hearings on H.R. 1627. June 7.

Osteen, C. and F. Kuch (1986). Potential Bans of Corn and Soybean Pesticides: Economic Implications for Farmers and Consumers. Agricultural Economic Report no. 546.

'Pesticide Food Safety Act of 1994' (1994). 103 H.R. 4091.

'Pesticide Reform Act of 1994' (1994). 103 H.R. 4362.

'Pesticide Safety and Right-to-know Act of 1995' (1995). 104 H.R. 1771.

Pimentel, D., L. McLaughlin, A. Zepp, B. Lakitan, T. Kraus, P. Kleinman, F. Vancini, W. John Roach, E. Graap, W. S. Keeton and G. Selig (1991). 'Environmental and economic impacts of reducing U.S. agricultural pesticide use'. Handbook of Pest Management in Agriculture. Vol 1. 2nd edition. London: CRC Press International.

'Pure-Food Act of 1906' (1906). Public Law 59-384, Cong. Ch. 3915; 34 Stat. 768, June 30.

Roe, D., W. Pease, K. Florini and E. Silbergeld (1997). Toxic Ignorance: Full Report. New York: Environmental Defense Fund, Summer.

'Safe Drinking Water Act Amendments of 1996' (1996). Public Law 104-182, S 1316.

Schierow, L. J. (1996). 'Pesticide legislation: Food Quality Protection Act of 1996 (P.L. 104-170)'. CRS Report for Congress 96-759 ENR. September 11.

Smith, D. (1999). 'Worldwide trends in DDT levels in human breast milk', International Journal of Epidemiology 28: 179-188.

Simon, Herbert, A. (1983). Reason in Human Affairs. Stanford: Stanford University Press.

Stern, P. C. and Harvey, V. F. (eds.) (1996). Understanding Risk: Informing Decisions in a Democratic Society. Washington, DC: National Academy Press.

'Toxic Substances Control Act of 1976' (1976). Public Law 94-469.

U.S. Congress (1992). Senate Committee on Governmental Affairs. Hearings: Government Regulation of Reproductive Hazards, Washington, DC: U.S. Government Printing Office, October 2.

U.S. Congress (1993). Joint Hearings: Safety of Pesticides in Food. Washington, DC: U.S. Government Printing Office.

U.S. 9th Circuit Court of Appeals (1992). Les vs. Reilly. CA 9, No. 91-70234, July 8.

U.S. District Court (1995). Case No. CIVS 89-0752, WBS-GGH. People of the State of California vs. Browner Consent Decree.

U.S. District Court (2001). Case No. C-99-3701CAL. Amended Partial Consent Decree. September 25.

U.S. General Accounting Office (2001). 'Agricultural Pesticides: Management Improvements Needed to Further Promote Integrated Pest Management', GAO-01-815, August 17.

vom Saal, F., B. G. Timms, M. M. Montano, P. Palanza, K. A. Thayer, S. C. Nagel, M. D. Dhar, V. K. Ganjam, S. Parmigiani and W. V. Welshons (1997). Prostate enlargement in mice due to fetal exposure 
to low doses of estradiol or diethylstilbestrol and opposite effects at high doses. Proc. Natl. Acad. Sci., USA 94:2056-2061.

Wargo, John (1996). Our Children's Toxic Legacy. New Haven: Yale University Press.

Waxman, Representative Henry (2002). Website. Issues and Legislation, Environment - Pesticides. http://www.waxman.house.gov/issues/environment/pesticides/issues_environment_pesticides.htm.

Wiles, R. and C. Campbell (1993). Pesticides in Children's Food. Environmental Working Group. Washington DC, June.

World Wildlife Federation (1992). Pesticide Reduction Programmes in Denmark, The Netherlands, and Sweden. November.

Zoeller, R. T., A. L. S. Dowling, C. T. A. Herzig, E. A. Iannacone, K. J. Gauger, and R. Bansal (2002). 'Thyroid hormone, brain development and the environment', Environmental Health Perspectives. 110: $355-361$. 